\title{
Modifiable Factors Influencing Resilience among Medical Interns
}

\author{
Ong Yu Xuan, Nurulhuda Mat Hassan*, Norwati Daud, \\ Nik Nor Ronaidi Nik Mahdi, Mohd Salami Ibrahim and Yuzana Mohd Yusop \\ Faculty of Medicine, University Sultan Zainal Abidin, Kuala Terengganu, Terengganu - 20400, \\ Malaysia; oyx1995@gmail.com, nurulhudamh@unisza.edu.my,norwati@unisza.edu.my, \\ nikronaidimahdi@unisza.edu.my, salamibrahim@unisza.edu.my, yuzanayusop@unisza.edu.my
}

\section{Abstract}

Resilience among the medical interns is essential and is protective against the state of burnout. However, it is not thoroughly investigated among medical interns. Is there any behavioural and modifiable factors influencing resilience? The objective of this study is to determine the level of resilience among medical interns in Malaysia and its associated factors. This nationwide cross-sectional study recruited medical interns from 17 randomly selected Malaysian hospitals accredited for medical intern training. All medical interns who reported to the selected hospitals from January to April 2020 were invited to answer an online questionnaire. The questionnaire incorporated Connor-Davidson Resilience Scale-10 (CD-RISC-10) for resilience, USMEQ-i to measure emotional quotient, Brief-Cope to assess coping styles, Preparedness for Hospital Practice Questionnaire (PHPQ test) to assess internship preparedness and questions related to sociodemographic, undergraduate training and interest to become a doctor. 524 from 870 medical interns (60.2\%) responded. Mean resilience score was $28.6(\mathrm{SD}=6.33)$. Significant factors associated with resilience include active involvement in sports $(\mathrm{p}=0.002)$, high EQ $(\mathrm{p}<0.001)$, interest to become a doctor $(\mathrm{p}<0.001)$, coping using humour $(\mathrm{p}<0.001)$, less coping by venting $(\mathrm{p}<0.001)$ and no failures in any clinical posting $(p=0.012)$. The regression model was substantiated by adjusted R2 of $62.8 \%$. Factors affecting resilience among medical interns include modifiable factors such as coping styles and involvement in sports. The findings could guide targeted intervention to promote during medical schools or internship preparation programmes to increase resilience among medical interns.

Keywords: Coping Styles, Emotional Intelligence, Medical Interns, Resilience

\section{Introduction}

The medical internship is a stressful period, partly driven by a great emphasis on vigorous training for safe and competent medical practice. During this period, medical interns are often exposed to negative situations which may lead to burnout; a state of exhaustion that is vital to be avoided among healthcare workers. Resilience is shown to be protective towards having burnout state and is a crucial element in an individual medical intern.

A medical intern, also known as a house officer or trainee doctor is defined as a young or junior doctor who has just completed medical school ${ }^{1}$. Medical interns are involved in training called housemanship or internship at a hospital, which is a period of medical training that transforms an academically qualified medical student

*Author for correspondence 
into a competent medical resident ${ }^{2}$. In Malaysia, medical graduates need to undergo internship for at least two years at the government Health Ministry's facilities before they are accepted to work with the ministry as a contract or permanent post, depending on their performance. The period may be extended up to three years if performance is unsatisfactory. Thus, internship training exerts physical, mental and emotional challenges which prepare the junior doctors for the life of real medical careers ahead ${ }^{3}$.

These dilemmas emphasize the importance of resilience among medical interns to perform well during the internship ${ }^{4}$. Resilience is described as a dynamic process enveloping positive transformation within the context of critical adversity ${ }^{5}$. It ensures one's optimal mental health regardless of adversity ${ }^{6}$. Resilience enables one to adapt to the negative impacts of stress, allow them to 'bounce back', or overcome adversity ${ }^{7}$. Professional resilience reduces burnout rate, at the same time, empowers positive adjustment and creates individual assets 5 . Health professional resilience is multifarious, gathering discrete personal traits alongside personal, social and workplace highlights ${ }^{8}$. Consequently, resilience contributes towards improved work performance and life experience?.

Previous studies show factors that can influence resilience include personal factors ${ }^{10}$, environmental factors and other unmodifiable factors. Personal factors are divided into positive and negative factors. Negative factors including burnout ${ }^{7,11,12}$ and depression ${ }^{13}$, adverse workplace challenges ${ }^{8}$. Positive factors including optimism, social support $^{14-18}$, positive emotion regulation like hope and coping strategy ${ }^{16,19,20}$, self-compassion and mindfulness ${ }^{21}$, family support and marital status ${ }^{7}$, established personal relationships and peer support ${ }^{22}$. Unmodifiable factors like age, race and gender also influence resilience ${ }^{23,24}$.

Studies that examine the relationship between resilience and their associated factors among medical interns are still scarce, especially in Malaysia ${ }^{25,26}$. Accordingly, gaps to be investigated in this research relate to the lack of quantitative description of resilience as a product of other variables. What is important is for this research to seek empirical evidence of the roles of factors that influence resilience as they are skills that can be modified, enhanced, taught and learned ${ }^{10,27,28}$. Resilience training is an effective educational program to help medical trainees manage their feelings of distress during residency training ${ }^{29}$. Therefore this study was done to find out the resilience level of medical interns in Malaysia and its associated factors. The result of this study hopefully can propose solutions to enhance these factors during undergraduate training.

\section{Methods}

\subsection{Study Design}

A nationwide cross-sectional study was conducted among medical interns in Malaysia. 17 out of 48 Malaysian hospitals accredited for medical intern training were selected using simple random sampling using Excel software.

\subsection{Sample Size}

For the sample size determination, the sample size was calculated for all objectives and the largest sample size was obtained using single mean formula as below:

Sample size, $\mathrm{n}=(\mathrm{Z} \sigma) / \Delta)^{2}$

$\mathrm{n}=$ Minimum required sample size.

$\Delta=$ absolute error from mean on either side/precision $=0.8$.

$\sigma=$ previous study standard deviation $(\mathrm{SD})=9.25$ (43).

$\mathrm{Z}=1.96(95 \% \mathrm{CI})$ when $\alpha=0.05$.

The minimum sample size is 514 .

After considering a $40 \%$ dropout, the sample size was 867 subjects.

\subsection{Recruitment of Subjects}

All medical interns who reported to the selected hospitals from January to April 2020 were invited to answer an online questionnaire.

The study participants were medical interns who were newly enrolled in an internship in the selected hospitals during the data collection period. The inclusion criteria are newly registered medical interns who understand both English and Malay language. The exclusion criteria were medical interns who are doing internship training partly abroad and those who do not have any smart phones.

\subsection{Ethical Approval}

Ethical approval was obtained from the National Medical Research Register in January 2020(NMRR-19-349951724 (IIR). Approval was also taken from the Hospital Directors of the respective hospitals involved in the study. 


\subsection{Method of Data Collection}

Data were collected using self-administered online questionnaires using Google form distributed together with the consent form and research information which described the purpose and detail of the study as well as the confidentiality of the data. A research assistant explained the research and provided a link to the Google Form to the interns after they reported as medical interns at the respective hospitals.

\subsection{Research Tools}

This questionnaire was written in English language and comprised of 5 sections of structured questions which took around 15 minutes to complete.

Part A contained background information of the respondents; age, gender, race, marital status, medical school details and activities during medical schools such as involvement in sports, any failures during clinical years and interest to become a doctor. Interest to become a doctor was measured using Likert scale of agreement to the statement. "I am very interested to become a medical doctor" (1- very much disagree to 5 - very much agree). Part B to E contained validated questionnaires which are Preparedness of Hospital Practice Questionnaire (PHPQ), CD-RISC 10, USMEQ-I, Brief-COPE, and Duke University Religion Index (DUREL).

CD-RISC 10 was used to measure resilience. This questionnaire has been widely used to measure resilience internationally. The CD-RISC 10 is a 10 -item scale that aims to determine the ability to deal effectively with stress and adversity and is in a range of 0 to 40 . The CD-RISC in the present study demonstrated a reliable measurement (Cronbach alpha of 0.92) in assessing resilience ${ }^{30}$.

As for preparedness for the practice of medical interns, it was assessed using the Preparedness of Hospital Practice Questionnaire (PHPQ). The questionnaire assessed medical intern's preparedness in the areas of IT skills, holistic skills, ethic and legal skills, patient management skills, scientific knowledge and clinical skill with a scale of 1 (very inadequate) to 5 (very adequate) for each item and finally described by average mean of all items. It was a validated questionnaire with a Cronbach alpha value of $0.86^{31}$.

The emotional intelligence of medical interns was measured using USMEQ-i which is a validated questionnaire with a Cronbach alpha value of $0.95^{32}$. The questionnaire contained 13 items with a scale of 0 (not like me) to 4 (totally like me) for each item. The final score for EQ used in this study is the total of the all items score as well as the mean score. Meanwhile, the religiosity of medical interns was assessed via DUREL using a total score of five items. It is a brief and easy-to-use instrument for the measurement of religious commitment with a Cronbach alpha value of $0.78^{33}$.

Coping style was assessed via the 28-item Brief-COPE which had 14 subscales, namely active coping, planning, positive reframing, acceptance, humour, religion, using emotional support, using instrumental support, selfdistraction, denial, venting, substance abuse, behavioural disengagement, and self-blame. The Cronbach alpha ranged from 0.43 to 0.88 . The subscales were then regrouped into Avoidant Coping and Approach Coping ${ }^{34}$. In this study, analysis was done for both 14 subscales and regrouped subscales.

\section{Statistical Analysis}

The data was checked, explored and cleaned. Data entry and analyses were done using SPSS for Windows version 25.0. Descriptive analysis was used to describe the sociodemographic and level of resilience of the respondents. All continuous variables were described using mean and Standard Deviation (SD) whereas categorical data as frequency and percentage (\%). Both univariable and multivariable analyses were performed to determine the associated factors for resilience. The independent variables were the socio-demographic data, undergraduate education and activities, interest, EQ score, PHPQ score, coping styles and religiosity. The dependent variable was the resilience score of medical interns in Malaysia. For univariate analysis, simple linear regression was used as screening in the selection of variables for further steps in multivariable analysis. Variables with a p-value $<0.25$ were selected for multivariable analysis to obtain the preliminary main effect model.

Multicollinearity and all possible two-way or first-order interactions were checked. Assumptions, overall model fitness, functional forms of variables and outliers were checked before obtaining the final model. Unstandardized predicted values and standardized residuals were calculated from the fitted model. Normality was checked by histogram plotting of standardized residuals. Scatter plots of standardized residuals on the $\mathrm{y}$-axis and unstandardized predicted values on the $\mathrm{X}$-axis 
established the linearity and equal variance assumptions as they appeared to be randomly scattered on both sides and along the zero lines. This reflected a good overall fitness of the model. Equal variance assumption was satisfactory as the dispersion from the zero lines appeared to be constant along with the unstandardized predicted value.

A scatter plot of the standardized residuals on the $\mathrm{Y}$-axis and the numerical independent variables on the $\mathrm{X}$-axis was made to check the appropriateness of the functional forms of the variables. A scatter plot of the standardized residuals on the Y-axis and the numerical independent variables not in the model on the $\mathrm{X}$-axis was also made to check for any relationship with outcome variables. After the assumptions and fitness were satisfied, the best fit model was obtained and presented with crude and adjusted regression coefficients, 95\% Confidence Intervals (CI), t-statistics with degrees of freedom, their corresponding $\mathrm{p}$-values, and overall $\mathrm{R}^{2}$ values.

\section{Results}

A total of 524 from 870 medical interns $(60.2 \%)$ responded. 175 (33.4\%) were males and 349 (66.6\%) were females. The median age for the medical interns was $26(\mathrm{IQR}=11)$. Of these, majority were Malays 69.1\% ( $n=262)$, Muslims $69.8 \%(\mathrm{n}=366)$ and from overseas medical schools $53.4 \%$ $(\mathrm{n}=280)$. Of the sample, $12.3 \%(\mathrm{n}=64)$ of the medical intern 477 (91\%) were assigned to the ministry's hospital while $44(8.4 \%)$ were assigned to universities' hospitals. The majority of them were active in sports and student body activities during medical school. The majority (75.6\%) did not fail any clinical postings (Table 1 ).

Table 1. Respondents profile and socio-demographics descriptive analysis $(\mathrm{n}=524)$

\begin{tabular}{|l|l|l|l|}
\hline \multicolumn{2}{|l|}{ Variable } & $\mathrm{n}(\%)$ & Mean (SD) \\
\hline \multicolumn{2}{|l|}{ Gender } & & \\
\hline & Male & $175(33.4)$ & \\
\hline & Female & $349(66.6)$ & \\
\hline \multicolumn{2}{|l|}{ Race } & & \\
\hline & Malay & $362(69.1)$ & \\
\hline & Chinese & $75(14.3)$ & \\
\hline & Indian & $76(14.5)$ & \\
\hline & Others & $11(2.1)$ & \\
\hline
\end{tabular}

\begin{tabular}{|l|l|l|l|}
\hline \multicolumn{1}{|l|}{} & & \\
\hline \multicolumn{2}{|l|}{ Marital Status } & & \\
\hline & Single & $447(85.5)$ & \\
\hline & Married & $76(14.5)$ & \\
\hline & & & \\
\hline \multicolumn{2}{|l|}{ Religion } & & \\
\hline \multicolumn{2}{|l|}{ Islam } & $366(69.8)$ & \\
\hline & Buddha & $59(11.3)$ & \\
\hline & Christian & $28(5.4)$ & \\
\hline & Others & $71(13.5)$ & \\
\hline & & & \\
\hline $\begin{array}{l}\text { Type of } \\
\text { medical school }\end{array}$ & $\begin{array}{l}\text { Overseas } \\
\text { school }\end{array}$ & $280(53.4)$ & \\
\hline & $\begin{array}{l}\text { Local } \\
\text { school }\end{array}$ & $186(35.5)$ & \\
\hline & Twinning & $58(11.1)$ & \\
\hline & No & $235(55.0)$ & \\
\hline $\begin{array}{l}\text { Type of } \\
\text { medical school }\end{array}$ & $\begin{array}{l}\text { Public } \\
\text { medical } \\
\text { school }\end{array}$ & $255(48.7)$ & \\
\hline $\begin{array}{l}\text { Interest in } \\
\text { becoming a } \\
\text { doctor }\end{array}$ & $\begin{array}{l}\text { Private } \\
\text { medical } \\
\text { school }\end{array}$ & $269(51.3)$ & \\
\hline $\begin{array}{l}\text { Active in } \\
\text { Student Body } \\
\text { Activities }\end{array}$ & Yes & \\
\hline failure & Yes & \\
\hline & Yes & $128(24.4)$ & \\
\hline & No & $396(75.6)$ & \\
\hline $\begin{array}{l}\text { Active in } \\
\text { Sports }\end{array}$ & & \\
\hline & & \\
\hline & Yes & \\
\hline
\end{tabular}




\begin{tabular}{|c|c|}
\hline Resilience & $28.6(6.33)$ \\
\hline $\begin{array}{l}\text { Preparedness } \\
\text { for practice } \\
\text { Emotional } \\
\text { intelligence }\end{array}$ & $\begin{array}{l}3.14(0.49) \\
3.08(0.58)\end{array}$ \\
\hline
\end{tabular}

\subsection{Resilience}

The mean score for resilience among medical interns in Malaysia was $28.6(\mathrm{SD}=6.33)$ with their scores ranging from 9 to 40 (Table 1).

Table 2 showed the significant associated factors for resilience among participants. All sociodemographic factors such as gender and age did were not significantly associated with resilience.

There was a significant linear positive relationship between active involvements in sports activities during medical school, interest to become a doctor, EQ, coping with humour with resilience. Those who scored 1-unit higher in interest had a 0.81 unit higher score in resilience (adjusted $\mathrm{b}=0.81,95 \%$ CI $0.37,1.25, \mathrm{p}<0.001$ ). Those who were active had 1.09 score unit higher in resilience as compared to those who are not active in sports (adjusted $\mathrm{b}=1.09,95 \%$ CI $0.39,1.79, \mathrm{p}=0.002)$. Those who had 1-unit higher score in emotional intelligence had a 0.56 score unit higher in resilience (adjusted $\mathrm{b}=0.56,95 \% \mathrm{CI}$ $0.51,0.61, \mathrm{p}<0.001)$. Those who had a 1-unit higher score in coping with humour subscale had a 0.54 unit higher score in resilience (adjusted $\mathrm{b}=0.54,95 \%$ CI $0.34,0.74$, $\mathrm{p}<0.001)$.
There was a significant linear negative relationship between fail clinical (history of failure in a medical school clinical examinations) and coping via venting and resilience. Those who had failed any clinical examinations had a 1.00 unit lower score in resilience as compared to those who never failed (adjusted $b=-1.00,95 \%$ CI -1.78 , $-0.22, p=0.012$ ). Those who had 1-unit higher score in coping via venting had a 0.45 score unit lower in resilience (adjusted $\mathrm{b}=-0.4595 \% \mathrm{CI}-0.68,-0.23, \mathrm{p}<0.001$ ).

In the linear regression model, interest to become a doctor, being active in sports, higher emotional intelligence, coping using humour, no failures during clinical years and less coping by venting explained $62.8 \%$ of the variation in resilience score among medical interns $\left(\mathrm{R}^{2}=0.63\right)$.

\section{Discussion}

The mean resilience score of medical interns was 28.60, which score more than half out of 40 maximum points. However, the mean score was lower compared to the elderly population aged 60 and above which had a mean score of $32^{35}$ and a student sample in the United States which was $30.1^{36}$. Our sample population had a median age of 26 . This mean score was also lower than the mean score manifested among medical students in Canada $^{37}$ and nursing students in Australia where the mean score was $32^{38}$. However, it was higher compared to the mean resilience score found in nursing students in India (mean $=26.3)^{39}$ and comparable to university students in Hungary $(\text { mean }=28.2)^{40}$ and dental students in Spain $(\text { mean }=27.8)^{41}$. This indicates medical interns in Malaysia had a lower resilience compared to the Western

Table 2. The associated factor for resilience among medical interns in Malaysia

\begin{tabular}{|l|l|l|l|l|l|l|l|}
\hline Factors & \multicolumn{3}{|c|}{ Simple Linear Regression } & \multicolumn{4}{c|}{ Multiple Linear Regression } \\
\hline & Crude b & $\mathbf{9 5 \% ~ C I ~}$ & P-value & Adj. b & 95\% CI & t-stat & P-value \\
\hline Interest & 3.09 & $2.50-3.67$ & $<0.001$ & 0.81 & $0.37-1.25$ & 3.61 & $<0.001$ \\
\hline Active sports & 3.11 & $2.03-4.20$ & $<0.001$ & 1.09 & $0.38-1.79$ & 3.05 & 0.002 \\
\hline Fail clinical & -1.57 & $(-2.83)-(-0.31)$ & 0.015 & -1.00 & $(-1.78)-(-0.22)$ & -2.52 & 0.012 \\
\hline Emotional intelligence & 0.63 & $0.59-0.68$ & $<0.001$ & 0.56 & $0.51-0.61$ & 22.47 & $<0.001$ \\
\hline Coping humor & 0.45 & $0.15-0.75$ & 0.003 & 0.54 & $0.34-0.74$ & 5.34 & $<0.001$ \\
\hline Coping venting & -0.78 & $(-1.12)-(-0.45)$ & $<0.001$ & -0.45 & $(-0.69)-(-0.23)$ & -3.95 & $<0.001$ \\
\hline
\end{tabular}

The model reasonably fits; model assumptions were met; no multicollinearity problem or interactions between independent variables were found.

$\mathrm{R}^{2}=0.63$ 
and adult population, but comparable to university students of other countries. This may be the result of multiple environmental factors which also attributed to the generation difference as compared to the previous adult study population.

There was no much difference in resilience score between genders in this study. This is in contrast to a few studies where a significant difference in resilience scores between gender was found ${ }^{36,42}$. However, the same results were achieved by research that studied the relationship between gender and resilience among college students ${ }^{43}$. A study among 100 adults also demonstrated that gender differences were not significant and there was no effect of gender on the level of resilience ${ }^{44}$. The mixed results implied that different results could be acquired in different study populations which may indicate a cultural and upbringing influence as well.

The study revealed a strong positive relationship between resilience and being active in sports among medical interns. Previous literature well-supported the findings which mentioned that active involvement in physical activity can enhance resilience through the taskoriented motivational climates in sports ${ }^{45}$. Another study explains the development of task-oriented motivational climates in sports by coaches helps improve achievement and acts as a protective factor towards burnout and improves resilience.

The positive relationship between emotional intelligence and resilience among medical interns showed the importance of EQ. Emotional intelligence is considered an antecedent to resilience ${ }^{46}$. A person with higher emotional intelligence copes better with others and this potentially improves resilience. This is due to the nature of internship where teamwork is crucial and good interaction with patients, colleagues, seniors and consultants are paramount. There was also a moderate relationship between interest and resilience. A strong interest to pursue study in medicine among medical interns during their medical school is great support for them to build resilience and overcome the stress of internship. This result was consistent with previous literature ${ }^{47}$.

The study findings emphasize the influence of coping styles on resilience. Coping with humour can be advocated in handling day-to-day stress as it showed a positive relationship with resilience. Humour can be used as a coping mechanism to encounter any challenges faced in life as it improves resilience ${ }^{48}$. On the other hand, coping via venting was associated with lower resilience. Too much venting may cause someone to lose focus on solving the problem at hand. This may be a maladaptive coping mechanism that leads to an adverse effect on resilience ${ }^{49}$.

The significant association between any failures in medical school with lower resilience is worrying. One would hope that students who had recovered from failures learn to become more resilient. It may be that the low resilience had contributed to the failures during medical school. This is supported by a study that showed students who had failures in subjects in medical school were more likely to struggle in professional practice later on as they having lower resilience skills and harder to bounced back from their failure in the past ${ }^{50}$.

The results of the study could be helpful for healthcare professionals, medical faculties' educators, educational researchers and curriculum developers to organize some programs to enhance coping and resilience among medical students. Overall, the idea of resilience has important implications in the field of educational psychology in five main functions: Assessment, intervention, consultation, research and training. Information and concepts obtained from this study could help researchers study more on ways to improve resilience and thus help the medical students to manage and deal with their challenges in the future during their internship program.

Consequently, the findings of this research may give some guidance for medical schools to meet the accountability demands for producing resilient medical graduates to perform as interns in the future. As suggested in the recent studies, the variables used in this research can be learned and taught as a skill. Consequently, medical schools have a responsibility to establish policies to promote students' adaptability to cope with adversity and difficulties they faced and enhance their well-being through strong resilience skills. For example, the medical school curriculum can encourage their medical students to be actively involved in sports activities as this will increase their resilience skills as evidenced by the result of this study. Student welfare and mental health departments also need to play their part to enhance resilience and social support systems among medical students. Programs or seminars can be organized to improve their student resilience skill especially in improving coping mechanisms, interest, and emotional intelligence among the medical students. 


\section{Limitations and Future Research}

Despite having significant findings in this study, a few numbers of limitations have been identified. As a crosssectional study, it cannot allocate cause-and-effect relationships between variables. Secondly, more variables could have been added such as financial support, family support and some more specific health index, like depression in mental health and psychological well-being which affects resilience level. It might lead to a better model describing the link between resilience and other variables. In addition, to have a deeper understanding of the resilience idea, further qualitative research may help in assessing the interaction and experience of different associated factors among medical interns. In future studies, a longitudinal study is recommended to reveal the cause-and-effect relationship among the variables.

\section{Conclusion}

Having the interest to become a doctor, being active in sports, having higher emotional intelligence and coping styles were significant modifiable factors associated with resilience among medical interns in Malaysia. This infers that undergraduate training programs can potentially play a crucial role in developing resilience which is not only applicable for the examinations during medical school but also for the internship period. In addition, having failed in clinical and coping via venting, diminish medical interns' resilience, thus interventions targeting medical students should also emphasize solving these issues.

\section{Acknowledgment}

The authors would like to thank the Ministry of Education for the grant funding the research (RACER/1/2019/ SKK01/UNISZA//1) and extend gratitude towards the medical interns who participated voluntarily in the research.

\section{Declaration of Interest}

The authors declare no conflicts of interest.

The dataset used in the study is readily available and can be acquired by contacting the corresponding author.

\section{References}

1. Stoppler MC. Definition of Intern [Internet]. MedicineNet. 2019 [updated 2019; cited 2020 Nov 10]. https://www.medicinenet.com/script/main/art.asp?articlekey $=9956$

2. Al-Dubai SAR, Ganasegeran K, Perianayagam W, Rampal KG. Emotional burnout, perceived sources of job stress, professional fulfillment and engagement among medical residents in Malaysia. Sci World J. 2013; 2013. PMid: 24367238 PMCid: PMC3842044. https://doi. org/10.1155/2013/137620

3. Yeoh OC. Medical graduates and the pressure they face. New Straits Times [Internet]. 2016 Aug 1 [cited 2020 Nov 10]. https://www.nst.com.my/news/2017/03/162222/medical-graduates-and-pressures-they-face

4. Fertleman C, Carroll W. Protecting students and promoting resilience. BMJ. 2013; 347(7923). PMid: 23999895. https:// doi.org/10.1136/bmj.f5266

5. Jackson D, Firtko A, Edenborough M. Personal resilience as a strategy for surviving and thriving in the face of workplace adversity: A literature review. J Adv Nurs. 2007; 60(1):1-9. PMid: 17824934. https://doi.org/10.1111/j.13652648.2007.04412.x

6. Fortney L, Luchterhand C, Zakletskaia L. Abbreviated mindfulness intervention for job satisfaction, quality of life and compassion in primary care clinicians: A pilot study. 2013. PMid: 24019272 PMCid: PMC3767709. https://doi. org/10.1370/afm.1511

7. Taku K. Relationships among perceived psychological growth, resilience and burnout in physicians. Pers Individ Dif. 2014; 59:120-3. https://doi.org/10.1016/j. paid.2013.11.003

8. Matheson C, Robertson HD, Elliott AM, Iversen L, Murchie P. Resilience of primary healthcare professionals working in challenging environments: A focus group study. Br J Gen Pract. 2016; 66(648):e507-e515. PMid: 27162205 PMCid: PMC4917054. https://doi.org/10.3399/bjgp16X685285

9. Dyrbye LN, Power DV, Stanford Massie F, et al. Factors associated with resilience to and recovery from burnout: A prospective, multi-institutional study of US medical students. Med Educ. 2010; 44(10):1016-26. PMid: 20880371. https://doi.org/10.1111/j.1365-2923.2010.03754.x

10. Carver CS, Connor-Smith J. Personality and coping. Annu Rev Psychol. 2010; 61:679-704. PMid: 19572784. https:// doi.org/10.1146/annurev.psych.093008.100352

11. Cooke GPE, Doust JA, Steele MC. A survey of resilience, burnout and tolerance of uncertainty in Australian general practice registrars. BMC Med Educ. 2013; 13:2. PMid: 23294479 PMCid: PMC3563610. https://doi. org/10.1186/1472-6920-13-2 
12. Physician LRF, Seedat S, Emsley RA. The prevalence of burnout and depression in medical doctors working in the Cape Town Metropolitan Municipality community healthcare clinics and district hospitals of the Provincial Government of the Western Cape : A cross- sectional study The prevalence o. 2014; 6190. https://doi.org/10.1080/2078 6204.2013.10874418

13. Hamdan-mansour A, Hamdan-Mansour AHM. Correlates of resilience among university students. Eur Psychiatry. 2015; 30(4):1945. https://doi.org/10.1016/S0924-9338(15) 31485-1

14. Bonanno GA. Loss, trauma and human resilience: Have we underestimated the human capacity to thrive after extremely aversive events? Am Psychol. 2004; 59(1):20-8. PMid: 14736317. https://doi.org/10.1037/0003-066X.59.1.20

15. Rutter M. The promotion of resilience in the face of adversity. Fam Count Eff Child Adolesc Dev. 2006: 26-52. https:// doi.org/10.1017/CBO9780511616259.003

16. Tugade MM, Fredrickson BL. Regulation of positive emotions: Emotion regulation strategies that promote resilience. J Happiness Stud. 2007; 8(3):311-33. https://doi. org/10.1007/s10902-006-9015-4

17. Soenens B, Vansteenkiste M, Sierens E. How are parental psychological control and autonomy-support related? A cluster-analytic approach. J Marriage Fam. 2009; 71(1):187202. https://doi.org/10.1111/j.1741-3737.2008.00589.x

18. Dawson M, Pooley JA. Resilience: The role of optimism, perceived parental autonomy support and perceived social support in first year university students. J Educ Train Stud. 2013; 1(2):38-49. https://doi.org/10.11114/jets.v1i2.137

19. Othman N, Nasurdin AAM. Work engagement of Malaysian nurses : Exploring the impact of hope and resilience. Int J Soc Manag Econ Bus Eng. 2011; 5(12):395-9.

20. Unrath M, Zeeb H, Letzel S, Claus M. Identification of possible risk factors for alcohol use disorders among general practitioners in. 2012 Aug: 1-9. PMid:2 2915283. https:// doi.org/10.4414/smw.2012.13664

21. Olson K, Kemper KJ, Mahan JD. What factors promote resilience and protect against burnout in first-year pediatric and medicine-pediatric residents? J Evidence-Based Complement Altern Med. 2015; 20(3):192-8. PMid: 25694128. https://doi.org/10.1177/2156587214568894

22. Mokhtar Azizi NS, Azizi Z, Azrin Baharuddin HE, Abdul RazakF. Examining factors of resilience in built environment students: Malaysia Case Study. Int J Adv Res Eng Technol. 2020; 11(9):305-14. doi:10.34218/IJARET.11.9.2020.031

23. De Oliveira ACP, Machado APG, Aranha RN. Identification of factors associated with resilience in medical students through a cross-sectional census. BMJ Open. 2017; 7(11):1-8. PMid: 29133319 PMCid: PMC5695417. https:// doi.org/10.1136/bmjopen-2017-017189
24. Harris LS. Effects of gender and spirituality on adults' resilience to daily non-traumatic stressors. Diss Abstr Int Sect A Humanit Soc Sci. 2017; 78(4-A(E)).

25. Lee MN. Applying risk and resilience framework in examining youth's sustainability in coping with life's challenges. Int J Trade Econ Financ. 2011; 2(5):407-11. https://doi. org/10.7763/IJTEF.2011.V2.140

26. Lian SY, Tam CL. Work stress, coping strategies and resilience: A study among working females. Asian Soc Sci. 2014; 10(12):41-52. https://doi.org/10.5539/ass.v10n12p41

27. Fresco DM, Moore MT, Walt L, Craighead LW. Selfadministered optimism training: Mechanisms of change in a minimally supervised psychoeducational intervention. J Cogn Psychother. 2009; 23(4):350-67. https://doi. org/10.1891/0889-8391.23.4.350

28. Meevissen YMC, Peters ML, Alberts HJEM. Become more optimistic by imagining a best possible self: Effects of a two week intervention. J Behav Ther Exp Psychiatry. 2011; 42(3):371-8. PMid: 21450262. https://doi.org/10.1016/j. jbtep.2011.02.012

29. Bird A, Pincavage A. A curriculum to foster resident resilience. Med Ed PORTAL Publ. 2016; 12. PMid: 31008217 PMCid: PMC6464448. https://doi.org/10.15766/ mep_2374-8265.10439

30. Campbell-Sills L, Stein MB. Psychometric analysis and refinement of the Connor-davidson Resilience Scale (CD-RISC): Validation of a 10-item measure of resilience. 2007; 20(3):251-62. https://doi.org/10.1037/t09624-000

31. Hazilah N, Manaf A, Johari R, et al. Preparedness for hospital practice in assuring quality of care. TQM J. 2016; 28(6):834-46. https://doi.org/10.1108/TQM-06-2014-0053

32. Saiful M, Yusoff B. Stability of USMEQ-i in measuring emotional intelligence in medical students. 2012 Jun; 13.

33. Koenig HG, Bussing A. The Duke University Religion Index (DUREL): A five-item measure for use in epidemological studies. Religions. 2010; 1(1):78-85. https://doi. org/10.3390/rel1010078

34. Eisenberg SA, Shen BJ, Schwarz ER, Mallon S. Avoidant coping moderates the association between anxiety and patient-rated physical functioning in heart failure patients. J Behav Med. 2012; 35(3):253-61. PMid: 21660588. https:// doi.org/10.1007/s10865-011-9358-0

35. Levasseur M, Roy M, Michallet B, St-Hilaire F, Maltais D, Genereux M. Associations between resilience, community belonging, and social participation among community-dwelling older adults: Results From the Eastern Townships Population Health Survey. Arch Phys Med Rehabil. 2017; 98(12):2422-32. PMid: 28455192. https:// doi.org/10.1016/j.apmr.2017.03.025

36. Hartley MT. Assessing and promoting resilience: An additional tool to address the increasing number of college 
students with psychological problems. J Coll Couns. 2012; 15(1):37-51. https://doi.org/10.1002/j.2161-1882.2012.00 004.x

37. Rahimi B, Baetz M, Bowen R, Balbuena L. Resilience, stress and coping among Canadian medical students. Can Med Educ J. 2014; 5(1):e5-e12. https://doi.org/10.36834/ cmej.36689

38. Chamberlain D, Williams A, Stanley D, Mellor P, Cross W, Siegloff L. Dispositional mindfulness and employment status as predictors of resilience in third year nursing students: a quantitative study. Nurs Open. 2016; (4):212-21. PMid: 27708832 PMCid: PMC5050545. https://doi.org/10.1002/ nop2.56

39. Mathad MD, Pradhan B, Rajesh SK. Correlates and predictors of resilience among baccalaureate nursing students. J Clin Diagnostic Res. 2017; 11(2):JC05-8. PMid: 28384889 PMCid: PMC5376833. https://doi.org/10.7860/ JCDR/2017/24442.9352

40. Orosz G, Toth-Kiraly I, Buki N, Ivaskevics K, Bothe B, Fulop M. The four faces of competition: The development of the Multidimensional Competitive Orientation Inventory. Front Psychol. 2018 May; 9:1-16. PMid: 29872415 PMCid: PMC5972296. https://doi.org/10.3389/fpsyg.2018.00779

41. Montero-Marin J, Tops M, Manzanera R, Piva Demarzo MM, De Mon MÁ, García-Campayo J. Mindfulness, resilience and burnout subtypes in primary care physicians: The possible mediating role of positive and negative effect. Front Psychol. 2015Dec; 6:1-8. PMid: 26733900 PMCid: PMC4681844. https://doi.org/10.3389/fpsyg.2015.01895

42. Weidong J, Guoquan Z, Yaosheng P, et al. Relationship between resilience and social support, coping style of students in middle school. Eur Psychiatry. 2012; 27:1. https:// doi.org/10.1016/S0924-9338(12)75574-8

43. Anasuri S, Anthony K. Resilience levels among college students: A comparative study from two southern states in the
USA. IOSR J Humanit Soc Sci. 2018; 23(1):52-73. https:// doi.org/10.9790/0837-2301035273

44. Splan RK, Brooks RM, Porr S, Broyles TW. Resiliency and achievement goal orientation among agricultural students. NACTA J. 2011; 55(4):31.

45. Chacon-Cuberos R, Castro-Sanchez M, Perez-Turpin JA, Olmedo-Moreno EM, Ortega FZ. Levels of physical activity are associated with the motivational climate and resilience in university students of physical education from andalucía: An explanatory model. Front Microbiol. 2019 Aug; 10:1-11. PMid: 31447747 PMCid: PMC6691152. https:// doi.org/10.3389/fpsyg.2019.01821

46. Magnano P, Craparo G, Paolillo A. Resilience and emotional intelligence: Which role in achievement motivation Resiliencia e Inteligencia Emocional: qué rol tienen en la motivación al logro Resilience and emotional Intelligence. Int J Psychol Res. 2016; 9(1):9-20. https://doi. org/10.21500/20112084.2096

47. Keeton K, Fenner DE. Predictors of physician career satisfaction. Work-life balance and burnout. 2007; 109(4):949-55.PMid: 17400859. https://doi.org/10.1097/01. AOG.0000258299.45979.37

48. Cherry KE, Sampson L, Galea S, et al. Spirituality, humor and resilience after natural and technological disasters. J Nurs Scholarsh. 2018; 50(5):492-501. PMid: 30058284. https://doi.org/10.1111/jnu.12400

49. Stratta P, Capanna C, Dell'Osso L, et al. Resilience and coping in trauma spectrum symptoms prediction: A structural equation modeling approach. Pers Individ Dif. 2015; 77:5561. https://doi.org/10.1016/j.paid.2014.12.035

50. Patel RS, Tarrant C, Bonas S, Shaw RL. Medical students' personal experience of high-stakes failure: Case studies using interpretative phenomenological analysis. BMC Med Educ. 2015; 15(1):1-9. PMid: 25964102 PMCid: PMC4548844. https://doi.org/10.1186/s12909-015-0371-9 